\title{
A Simple Setup for Transfer Hydrogenations in Flow Chemistry
}

\author{
Matthew Hutchings \\ Thomas Wirth* \\ School of Chemistry, Cardiff University, \\ Cardiff CF10 3AT, UK \\ wirth@cf.ac.uk
}

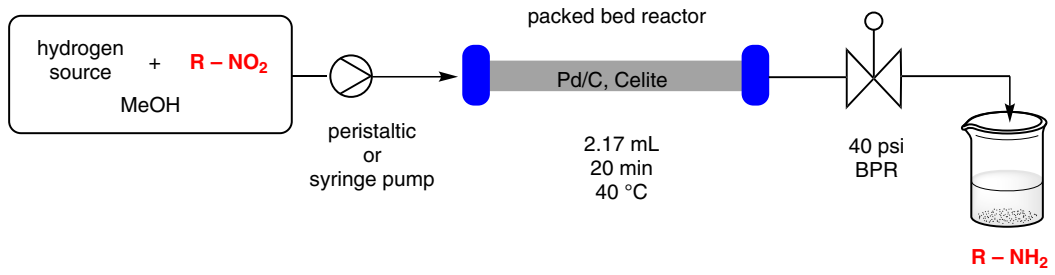

Received: 01.02.2016

Accepted after revision: 29.03.2016

Published online: 18.04 .2016

DOI: 10.1055/s-0035-1561624; Art ID: st-2016-d0074-|

Abstract By using a packed-bed reactor with a palladium/charcoal catalyst and ammonium formate or triethylsilane as hydrogen/hydride source, various functional groups including nitro groups, azides and alkenes can be efficiently reduced by a transfer hydrogenation process under mild conditions in a simple flow system.

Key words alkenes, flow chemistry, nitro compounds, packed bed reactor, transfer hydrogenation

Microreactors are nowadays common in many organic synthesis laboratories in both academia and industry. ${ }^{1}$ They have gained acceptance because they have been shown to run chemical transformations more efficiently, more selectively, and with a much higher degree of safety. ${ }^{2-9}$ Reduction chemistry is well suited to flow chemistry given the inherent risks involved in such transformations. ${ }^{10}$ Using hydrogen gas in industrial applications in large-scale batch reactors is undesirable and specialist equipment has to be used. Similar risks, although on a smaller scale, are apparent in synthetic laboratories, and equipment for flow hydrogenations with the generation of small amounts of hydrogen are commercially available. ${ }^{11}$ Although this is an established and reliable technique, it does come with a large price tag. Many groups have sought to find methods to perform hydrogenations and reductions by using simple equipment designs such as tube-in-tube reactors using hydrogen gas $^{12-15}$ and even supported-reagent-based cartridge systems using sodium borohydride. ${ }^{16}$ Herein, we report flow hydrogenations conducted by using a conventional multipurpose setup. This allows easy operation without the need to purchase specialist equipment and thereby provides access to hydrogenation facilities for a wide range of laboratories.
Metal-catalysed hydrogenations without elemental hydrogen are already known, and transfer hydrogenations have been investigated in batch chemistry. Some examples have also been reported in flow chemistry, such as the use of aqueous zirconia. ${ }^{17}$ Means et al. described a similar method using palladium for the reduction of alkenes. ${ }^{18} \mathrm{~A}$ column was filled with palladium black and gravity was used to flow a solution containing the substrate and formic acid through the column. A stop clock was adjusted to control residence times. Very good yields were obtained in a short reaction time. Although this method was highly successful, $5.6 \mathrm{mmol}$ of Pd for $1 \mathrm{mmol}$ of alkene was used. We report herein the development of a simple flow system with a fixed bed catalyst that can be used to perform catalytic hydrogenation reactions. We mainly investigated the reduction of nitro compounds to the corresponding amines, as shown in the general setup in Figure 1. The substrate (0.5 $\mathrm{M}$ in $\mathrm{MeOH}$ ) and reagent were premixed and introduced by using a single syringe. The hydrogen source was used in five-fold excess relative to the substrate and the stream was then fed into the catalyst-containing glass column connected through Teflon tubing and connectors. To allow for a steady stream, the system was connected to a backpressure regulator (BPR) of 40 psi. This allows for a homogeneous flow regime in the column without the formation of hydrogen gas influencing the flow rate.

Initially, the potential of the simple reactor in hydrogenation reactions was assessed with the hydrogenation of 2nitro-1-( $p$-tolyl)ethan-1-ol (1). This compound is easily accessible by the Henry reaction using $p$-tolualdehyde and nitromethane in combination with sodium hydroxide. ${ }^{19}$ In the reduction, different catalysts/reagents were used in the fixed bed reactor together with a range of hydrogen sources, as shown in Table 1. 


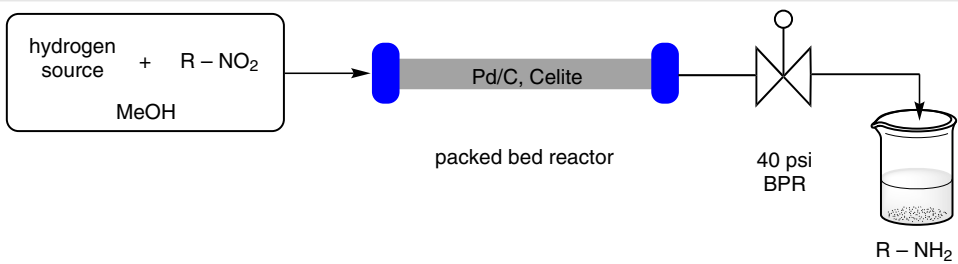

Figure 1 Flow setup for the reduction of nitro compounds using a packed-bed reactor in flow

The initial reaction was carried out at $20^{\circ} \mathrm{C}$ (Table 1 , entry 1 ), using conditions similar to previously reported procedures. The flow rate of $0.108 \mathrm{~mL} / \mathrm{min}$ corresponded to a residence time of $20 \mathrm{~min}$ within the reactor cartridge. Upon collection, it was shown that a conversion of $66 \%$ was achieved, as shown by ${ }^{1} \mathrm{H}$ NMR spectroscopic analysis. When the temperature of the reaction was increased to $40{ }^{\circ} \mathrm{C}$, the conversion increased to $91 \%$ (entry 2 ). Decreasing the number of equivalents of ammonium formate to 2.5 resulted in a drop in conversion to $71 \%$ (entry 3 ); whereas a larger number of equivalents of ammonium formate was not soluble. Furthermore, when the flow rate was increased to $0.216 \mathrm{~mL} / \mathrm{min}$ the conversion decreased substantially. For comparison, Raney nickel and further metallic reagents were also investigated for the reduction of $\mathbf{1}$. As shown in Table 1, the use of Raney nickel (entry 4 ) resulted in a lower conversion rate compared with $\mathrm{Pd} / \mathrm{C}$ under the same reaction conditions. For further comparison, non-catalytic methods were used to demonstrate the mild and efficient nature of this method. The combination of iron and acetic acid at $70{ }^{\circ} \mathrm{C}$ showed reasonable conversions in the reduction of $\mathbf{1}$, but under considerably harsher reaction conditions. The strongly acidic conditions may cause problems

Table 1 Catalysts and Reagents for the Reduction of 1 in Methanol ${ }^{\mathrm{a}}$
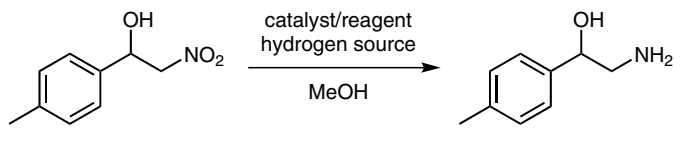

\begin{tabular}{lllll}
\hline Entry & Catalyst/reagent & Hydrogen source & Temp $\left({ }^{\circ} \mathrm{C}\right)$ & Conv. $(\%)^{\mathrm{b}}$ \\
\hline 1 & $\mathrm{Pd} / \mathrm{C}$ & $\mathrm{HCO}_{2} \mathrm{NH}_{4}$ & 20 & 66 \\
2 & $\mathrm{Pd} / \mathrm{C}$ & $\mathrm{HCO}_{2} \mathrm{NH}_{4}$ & 40 & 91 \\
3 & $\mathrm{Pd} / \mathrm{C}$ & $\mathrm{HCO}_{2} \mathrm{NH}_{4}$ & 40 & $71^{\mathrm{d}}$ \\
4 & Raney Ni & $\mathrm{HCO}_{2} \mathrm{NH}_{4}$ & 40 & 86 \\
5 & $\mathrm{Fe}$ & $\mathrm{ACOH}^{\mathrm{c}}$ & 70 & 60 \\
6 & $\mathrm{Zn}$ & $\mathrm{NH}_{4} \mathrm{Cl}$ & 40 & 85 \\
7 & $\mathrm{Sn}$ & $\mathrm{HCl}$ & 20 & 45 \\
\hline
\end{tabular}

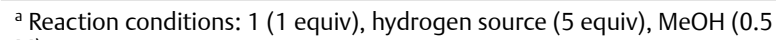

$\mathrm{M})$.

${ }^{\mathrm{b}}$ Determined by ${ }^{1} \mathrm{H}$ NMR spectroscopic analysis.

c Acetic acid was used as a co-solvent in a 1:1 ratio with methanol.

${ }^{d} \mathrm{HCO}_{2} \mathrm{NH}_{4}$ (3 equiv) was used. when moving to substrates with other functional groups. This would also be the case using tin and hydrochloric acid (entry 7). A slightly milder method is the combination of zinc and ammonium chloride (entry 6). This method allowed for conversion of $\mathbf{1}$ into $\mathbf{2}$, but was still not as high as with $\mathrm{Pd} / \mathrm{C}$. This clearly shows the superiority of the palladium on charcoal catalyst for the reduction of the nitro functionality.

After the initial optimisation, the substrate scope of this procedure was investigated (Table 2). Phenylnitromethane (3) could be cleanly reduced to benzylamine (4). Benzylazide (5) was reduced with similar efficiency, providing benzylamine (4) in 95\% yield. Aromatic nitro groups were also easily reduced to the corresponding aniline derivatives. 2-Nitrobenzoic acid (6) was efficiently reduced to anthra-

Table 2 Substrate Scope for the Reduction of Nitro Compounds Using Flow Conditions ${ }^{\mathrm{a}}$

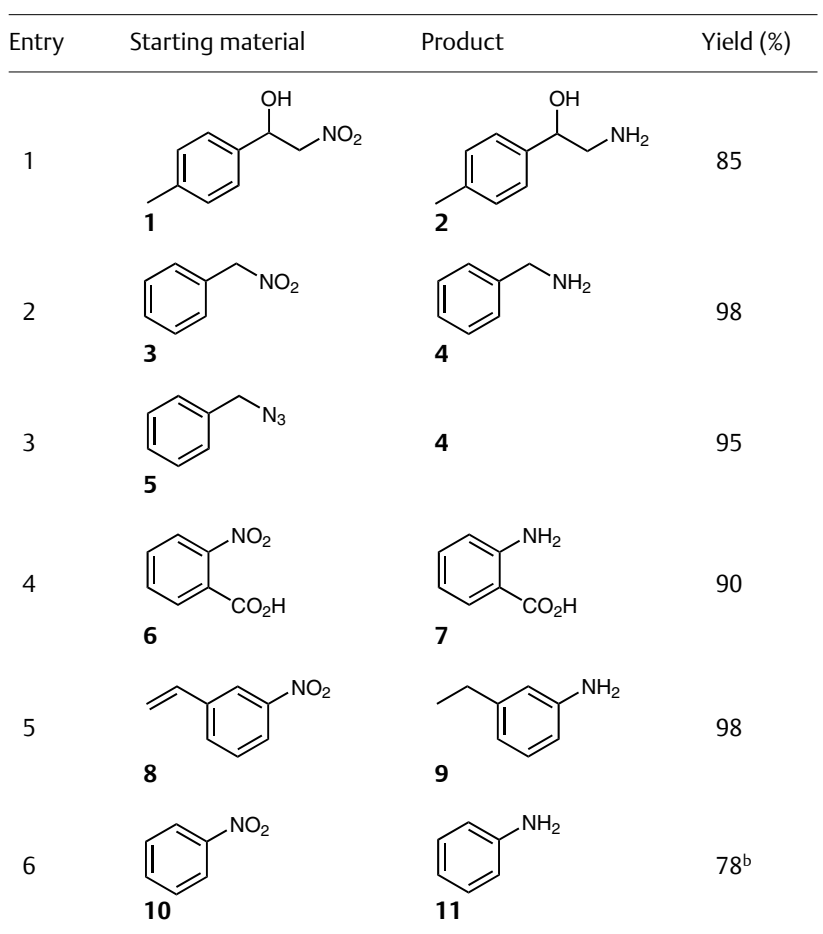

a Reaction conditions: nitro compound (1 equiv), ammonium formate (5 equiv), $\mathrm{MeOH}(0.5 \mathrm{M})$.

${ }^{\mathrm{b}}$ Reaction conducted on $10 \mathrm{mmol}$ scale. 
Table 3 Substrate Scope of Reductions of Olefinic Compounds Using Flow Conditions ${ }^{\mathrm{a}}$

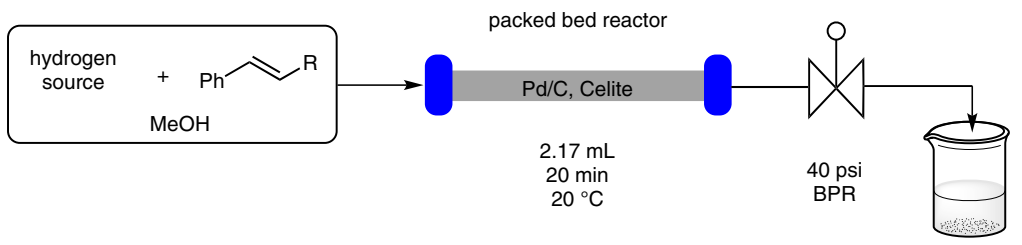

Entry

\footnotetext{
a Reaction conditions: substrate (1 equiv), hydrogen source ( 5 equiv), $\mathrm{MeOH}(0.5 \mathrm{M}), 20{ }^{\circ} \mathrm{C}$
}

${ }^{\mathrm{b}}$ Reaction carried out at $60{ }^{\circ} \mathrm{C}$.

nilic acid (7) under the reaction conditions, leaving the acid group intact. Interestingly, when 3-nitrostyrene (8) was used as substrate, both the nitro group and the double bond were reduced in almost quantitative yield. ${ }^{20}$

To gain further insight into the usefulness of this process, a larger scale reaction was carried out. By using 10 mmol nitrobenzene (10) dissolved in methanol in combination with ammonium formate, the reaction was run continuously for 100 minutes, leading to the isolation of 0.73 grams of aniline $(\mathbf{1 1} ; \mathbf{7 8 \%} \%$ ). To investigate possible leaching of the palladium catalyst, a simple experiment was devised. Nitrobenzene, ammonium formate and methanol were placed into a collection flask and a flow of further methanol was pumped into the flask, passing through the column into a collection flask. This was then stirred for 4 hours and characterised by ${ }^{1} \mathrm{H}$ NMR spectroscopic analysis. From the acquired spectra there was no evidence of the formation of aniline, therefore it can be concluded that no or very little palladium was leached from the column into the collection flask.

The reduction of the double bond in addition to the nitro functionality allowed an extension of the methodology to other substrates. Application of this method for the reduction of methyl cinnamate (12) proved to be only slightly successful, with some conversion within the 20 minutes of residence time. Even an increase of the reaction temperature to $60{ }^{\circ} \mathrm{C}$ had little effect (Table 3 , entry 2 ). However, changing the hydrogen source from ammonium formate to triethylsilane led to almost full conversion of the olefinic substrate (entry 3). The mild conditions did not affect the ester functionality, resulting in $97 \%$ yield of the reduction product 13.

The results shown here demonstrate a rapid, versatile and selective reducing system for a variety of functional groups. The method can also be used in the presence of other functional groups such as esters, carboxylic acids and nitriles. The use of ammonium formate as reductant has the advantages of being readily available, inexpensive, stable and non-toxic, and can be used in conjunction with either $\mathrm{Pd} / \mathrm{C}$ or Raney-Ni catalysts. Triethylsilane proved to be a superior hydrogen donor for double bonds, allowing the scope of substrates to be extended to $\alpha, \beta$-unsaturated compounds.

\section{Acknowledgment}

Support from the School of Chemistry, Cardiff University, is gratefully acknowledged.

\section{References and Notes}

(1) Microreactors in Organic Synthesis and Catalysis; Wirth, T., Ed.; Wiley-VCH: Weinheim, 2013.

(2) Watts, P.; Haswell, S. J. Chem. Soc. Rev. 2005, 34, 235.

(3) Geyer, K.; Codée, J. D. C.; Seeberger, P. H. Chem. Eur. J. 2006, 12, 8434.

(4) Ahmed-Omer, B.; Brandt, J. C.; Wirth, T. Org. Biomol. Chem. 2007, 5, 733.

(5) Yoshida, J.; Nagaki, A.; Yamada, T. Chem. Eur. J. 2008, 14, 7450.

(6) Webb, D.; Jamison, T. F. Chem. Sci. 2010, 1, 675. 
(7) Hartman, R. L.; McMullen, J. P.; Jensen, K. F. Angew. Chem. Int. Ed. 2011, 50, 7502.

(8) Wegner, J.; Ceylan, S.; Kirschning, A. Adv. Synth. Catal. 2012, 354 , 17.

(9) Gutmann, B.; Cantillo, D.; Kappe, C. O. Angew. Chem. Int. Ed. 2015, 54, 6688.

(10) Irfan, M.; Glasnov, T. N.; Kappe, C. O. ChemSusChem 2011, 4, 300.

(11) Bryan, M. C.; Wernick, D.; Hein, C. D.; Petersen, J. V.; Eschelbach, J. W.; Doherty, E. M. Beilstein J. Org. Chem. 2011, 7, 1141.

(12) O’Brien, M.; Taylor, N.; Polyzos, A.; Baxendale, I. R.; Ley, S. V. Chem. Sci. 2011, 2, 1250.

(13) Newton, S.; Ley, S. V.; Casas Arcé, E.; Grainger, D. M. Adv. Synth. Catal. 2012, 354, 1805.

(14) Ouchi, T.; Battilocchio, C.; Hawkins, J. M.; Ley, S. V. Org. Process Res. Dev. 2014, 18, 1560.

(15) Baumann, M.; Baxendale, I. R.; Hornung, C. H.; Ley, S. V.; Rojo, M. V.; Roper, K. A. Molecules 2014, 19, 9736.

(16) Gilmore, K.; Vukelić, S.; McQuade, D. T.; Koksch, B.; Seeberger, P. H. Org. Process Res. Dev. 2014, 18, 1771.

(17) Battilocchio, C.; Hawkins, J. M.; Ley, S. V. Org. Lett. 2013, 15, 2278.

(18) Elamin, B.; Park, J.-W.; Means, G. E. Tetrahedron Lett. 1988, 29, 5599.

(19) Ali, A.; Napolitano, J. M.; Deng, Q.; Lu, Z.; Sinclair, P. J.; Taylor, G. E.; Thompson, C. F.; Quraishi, N.; Smith, C. J.; Hunt, J. A.; Dowst, A. A.; Chen, Y.-H.; Li, H. PCT Int. Appl 2006014413, 2006.

(20) Fixed Bed Column Preparation: Portions of Celite (1.45 g) and $5 \% \mathrm{Pd} / \mathrm{C}(200 \mathrm{mg})$ were ground together with a mortar and pestle. After inserting the end-cap (with a $10-40 \mu \mathrm{m}$ filter) into a $150 \mathrm{~mm}$ Omni-Fit column (6.6 mm ID), the ground Celite/Pd/C mixture was packed by tapping on the benchtop and priming with solvent. The column was sealed with an end-cap. The column was further packed by flowing $\mathrm{MeOH}$ through the column at $0.5 \mathrm{~mL} / \mathrm{min}$ until no air bubbles were observed. The column volume, averaging $2.17 \mathrm{~mL}$, was determined from the difference between the anhydrous and wet weights divided by the density of the solvent $(\mathrm{MeOH})$.

General Procedure for Reductions: Nitro compound or olefin (5 mmol) and hydrogen source $(25 \mathrm{mmol})$ were dissolved in $\mathrm{MeOH}(10 \mathrm{~mL}, 0.5 \mathrm{M})$. After flushing the column with $\mathrm{MeOH}$, the substrate/reagent solution was pumped through the column at the specified temperature with a flow rate of 0.108 $\mathrm{mL} / \mathrm{min}$ by using Vapourtec E-series equipment (with a peristaltic pump). Alternatively, a syringe pump can be used. The first column volume was discarded, the second was collected. The solvent was evaporated, the residue added to distilled water $(20 \mathrm{~mL})$, and extracted with diethyl ether or dichloromethane $(3 \times 15 \mathrm{~mL})$. The combined organic phases were dried over $\mathrm{MgSO}_{4}$, filtered, and the solvent was removed in vacuo.

2-Amino-1-(p-tolyl)ethan-1-ol (2): Yield: $138 \mathrm{mg}$ (0.92 mmol, $85 \%)$; colourless solid; mp $139-140{ }^{\circ} \mathrm{C} .{ }^{1} \mathrm{H}$ NMR $\left(\mathrm{CDCl}_{3}, 400\right.$ $\mathrm{MHz}): \delta=7.18$ (d, J = 7.9 Hz, $2 \mathrm{H}), 7.08(\mathrm{~d}, \mathrm{~J}=7.8 \mathrm{~Hz}, 2 \mathrm{H}), 4.70$ (dd, J = 8.4, $2.8 \mathrm{~Hz}, 1 \mathrm{H}$ ), 3.57 (br s, $3 \mathrm{H}$ ), 2.99 (dd, J = 12.7, $3.4 \mathrm{~Hz}$, $1 \mathrm{H}), 2.84(\mathrm{dd}, \mathrm{J}=12.6,8.8 \mathrm{~Hz}, 1 \mathrm{H}), 2.30(\mathrm{~s}, 3 \mathrm{H})$; in agreement with reported literature data. ${ }^{21 a}$

Benzylamine (4): Yield: $113 \mathrm{mg}$ (1.06 mmol, 98\%); colourless liquid; ${ }^{1} \mathrm{H}$ NMR $\left(\mathrm{CDCl}_{3}, 400 \mathrm{MHz}\right): \delta=7.18-7.31(5 \mathrm{H}, \mathrm{m}), 3.81$ $(2 \mathrm{H}, \mathrm{s}) ;{ }^{13} \mathrm{C}$ NMR $\left(\mathrm{CDCl}_{3}, 100 \mathrm{MHz}\right): \delta=143.3,128.6,127.1$, $126.8,46.2$; in agreement with reported literature data. ${ }^{21 \mathrm{~b}}$

Anthranilic acid (7): Yield: $133 \mathrm{mg}(0.98 \mathrm{mmol}, 90 \%)$; off-white solid; mp 147-150 ${ }^{\circ} \mathrm{C} ;{ }^{1} \mathrm{H}$ NMR $\left(\mathrm{CDCl}_{3}, 400 \mathrm{MHz}\right): \delta=7.93$ (d, J = $8.1 \mathrm{~Hz}, 1 \mathrm{H}), 7.32(\mathrm{t}, \mathrm{J}=7.7 \mathrm{~Hz}, 1 \mathrm{H}), 6.67(\mathrm{~d}, \mathrm{~J}=7.2 \mathrm{~Hz}, 2 \mathrm{H}) ;{ }^{13} \mathrm{C}$ NMR $\left(\mathrm{CDCl}_{3}, 100 \mathrm{MHz}\right): \delta=173.6,151.6,135.6,132.6,117.2$, $116.9,109.9$; in agreement with reported literature data. ${ }^{21 c}$

3-Ethylaniline (9): Yield: $128 \mathrm{mg}(1.06 \mathrm{mmol}, 98 \%)$; paleyellow liquid; ${ }^{1} \mathrm{H} \mathrm{NMR}\left(\mathrm{CDCl}_{3}, 400 \mathrm{MHz}\right): \delta=7.08(\mathrm{t}, \mathrm{J}=7.7 \mathrm{~Hz}$, $1 \mathrm{H}), 6.62(\mathrm{~d}, \mathrm{~J}=7.5 \mathrm{~Hz}, 1 \mathrm{H}), 6.57-6.50(\mathrm{~m}, 2 \mathrm{H}), 3.25$ (br. s, $1.5 \mathrm{H}), 2.57$ (q, J = 7.5 Hz, $2 \mathrm{H}), 1.21(\mathrm{t}, \mathrm{J}=7.6 \mathrm{~Hz}, 3 \mathrm{H}) ;{ }^{13} \mathrm{C} \mathrm{NMR}$ $\left(\mathrm{CDCl}_{3}, 100 \mathrm{MHz}\right): \delta=146.4,145.7,129.2,118.4,115.0,112.5$, 28.9, 15.5; in agreement with reported literature data. ${ }^{21 \mathrm{~d}}$

Aniline (11): Yield: $0.73 \mathrm{~g}$ (7.85 mmol, 78\%); pale-yellow liquid; ${ }^{1} \mathrm{H} \mathrm{NMR}\left(\mathrm{CDCl}_{3}, 400 \mathrm{MHz}\right): \delta=7.17(\mathrm{~d}, \mathrm{~J}=7.5 \mathrm{~Hz}, 2 \mathrm{H}), 6.77$ (t, J $=7.4 \mathrm{~Hz}, 1 \mathrm{H}), 6.70(\mathrm{t}, \mathrm{J}=7.6 \mathrm{~Hz}, 2 \mathrm{H}) ;{ }^{13} \mathrm{C}$ NMR $\left(\mathrm{CDCl}_{3}, 100\right.$ $\mathrm{MHz}): \delta=146.5,129.4,118.7,115.2$.

Methyl 3-phenylpropanoate (13): Yield: $172 \mathrm{mg}(1.05 \mathrm{mmol}$, 97\%); colourless oil; ${ }^{1} \mathrm{H}$ NMR $\left(400 \mathrm{MHz}, \mathrm{CDCl}_{3}\right): \delta=7.25-7.30$ $(\mathrm{m}, 2 \mathrm{H}), 7.18-7.21(\mathrm{~m}, 3 \mathrm{H}), 3.66(\mathrm{~s}, 3 \mathrm{H}), 2.95(\mathrm{t}, \mathrm{J}=7.8 \mathrm{~Hz}$, $2 \mathrm{H}), 2.63(\mathrm{t}, \mathrm{J}=7.8 \mathrm{~Hz}, 2 \mathrm{H}) ;{ }^{13} \mathrm{C}$ NMR $\left(100 \mathrm{MHz}, \mathrm{CDCl}_{3}\right): \delta=$ $173.4,140.5,128.5,128.3,123.7,51.7,35.7,30.9$; in agreement with reported literature data. ${ }^{21 a}$

3-Phenylpropanenitrile (15): Yield: $113 \mathrm{mg}(0.86 \mathrm{mmol}, 80 \%)$; pale-yellow liquid; ${ }^{1} \mathrm{H}$ NMR $\left(\mathrm{CDCl}_{3}, 400 \mathrm{MHz}\right): \delta=7.25-7.31(\mathrm{~m}$, $5 \mathrm{H}), 2.99(\mathrm{t}, \mathrm{J}=7.4 \mathrm{~Hz}, 2 \mathrm{H}), 2.64(\mathrm{t}, \mathrm{J}=7.4 \mathrm{~Hz}, 2 \mathrm{H}) ;{ }^{13} \mathrm{C} \mathrm{NMR}$ $\left(\mathrm{CDCl}_{3}, 100 \mathrm{MHz}\right): \delta=138.3,129.2,128.6,127.8,119.5,32.1$, $19.6 \mathrm{ppm}$; in agreement with reported literature data. ${ }^{21 \mathrm{e}}$

(21) (a) Shang, G.; Liu, D.; Allen, S. E.; Yang, Q.; Zhang, X. Chem. Eur. J. 2007, 13, 7780. (b) Hemantha, H. P.; Sureshbabu, V. V. Org. Biomol. Chem. 2011, 9, 2597. (c) Regulska, E.; Samsonowicz, M.; Świsłocka, R.; Lewandowski, W. J. Mol. Struct. 2009, 936, 162. (d) Sharma, U.; Kumar, P.; Kumar, N.; Kumar, V.; Singh, B. Adv. Synth. Catal. 2010, 352, 1834. (e) Mori, N.; Togo, H. Synlett 2005, 1456. 